\title{
Jurnal
}

\section{Pengaruh Akuntabilitas Pengurus Organisasi Dalam Pengelilaan Keuangan Terhadap Kualitas Laporan Pertanggungjawaban (LPJ) Program Kerja}

\author{
Dewi Kusuma Wardani ${ }^{1}$, Anita Primastiwi ${ }^{2}$, Febby Gloria Usun ${ }^{3}$ \\ ${ }^{1,2,3}$ Fakultas Ekonomi, Universitas Sarjanawiyata Tamansiswa \\ dewifeust@gmail.com ${ }^{1}$; anita.primas@ustjogja.ac.id²; febbygloriausun@gmail.com³
}

Received 16 September 2021| Revised 01 November 2021 | Accepted 30 November 2021

*Korespondensi Penulis

\begin{abstract}
Abstrak
Tujuan dari penelitian ini adalah untuk mengetahui pengaruh akuntabilitas pengurus organisasi dalam pengelolaan keuangan terhadap kualitas laporan pertanggungjawaban program kerja (LPJ). Penelitian ini menggunakan jenis penelitian kuantitatif. Pengumpulan data menggunakan data primer dengan membagikan kuesioner kepada mahasiswa yang mengikuti kepengurusan organisasi kelembagaan dan UKM di Universitas Sarjanawiyata Tamansiswa Yogyakarta. Pengambilan sampel dilakukan dengan menggunakan teknik convenience sampling. Data penelitian dikumpulkan melalui menggunakan kuesioner melalui link google form dan dikirimkan via whatsapp kepada mahasiswa. Jumlah kuesioner yang diolah ialah sebanyak 100 kuesioner. Data penelitian dianalisis dengan menggunakan path analysis. Penelitian ini menyatakan bahwa akuntabilitas dalam pengelolaan keuangan organisasi di Universitas Sarjanawiyata Tamansiswa berpengaruh positif terhadap kualitas laporan pertanggungjawaban program kerja.
\end{abstract}

Kata Kunci: Akuntabilitas; Kualitas Laporan; Pertanggungjawaban (LPJ)

\begin{abstract}
The purpose of this study was to determine the effect of organizational management accountability in financial management on the quality of the work program accountability report (LPJ). This research uses quantitative research. Collecting data using primary data by distributing questionnaires to students who take part in the management of institutional and SME organizations at the Bachelorwiyata University Tamansiswa Yogyakarta. Sampling was done using convenience sampling technique. Research data was collected using a questionnaire via a google form link and sent via whatsapp to students. The number of questionnaires that were processed were 100 questionnaires. The research data were analyzed using path analysis. This study states that accountability in organizational financial management at the University of Sarjanawiyata Tamansiswa has a positive effect on the quality of work program accountability reports.
\end{abstract}

Keywords: Accountability, Quality of Accountability Report

\section{PENDAHULUAN}

Perguruan tinggi atau kampus merupakan organisasi sektor publik yang mendapatkan uang dari negara. Yang mana, uang tersebut harus dikelola dan dialokasikan untuk pembangunan berkelanjutan yang ada pada kampus tersebut dan juga untuk membiayai organisasi-organisasi yang berada dibawah naungan kampus tersebut (Hanifa, 2019). Di antara organisasi-organisasi di naungi oleh Universitas Sarjanawiyata Tamansiswa, terdapat organisasi mahasiswa tingkat Universitas seperti MMU (Majelis Mahasiswa Universitas), UKM (Unit Kegiatan Mahasiswa). Pada tingkat fakultas terdapat juga organisasi mahasiswa seperti MMF (Majelis Mahasiswa Fakultas) dan ada juga organisasi UKM (Unit 
Kegiatan Mahasiswa) tingkat fakultas. Tingkat jurusan terdapat juga organisasi mahasiswa seperti Ikatan Mahasiswa Program Studi (IMPS).

Laporan pertanggungjawaban program kerja akan menjadi bukti bahwa pengelolaan keuangan sudah dilaksanakan dan program kerja telah terealisasi dengan baik dan benar sesuai dengan prosedur yang sudah di tentukan oleh pihak kampus. Seperti dalam berita Antaranews Aceh (2019) yang mana dalam berita tersebut memaparkan bahwa Badan Pemeriksaan Keuangan (BPK) Republik Indonesia menggelar kuliah umum di Universitas Syiah Kuala Darussalam Banda Aceh dengan tema peran BPK dalam mendorong transparansi akuntabilitas pengelolaan keuangan negara dalam upaya meningkatkan pemahaman mahasiswa terhadap cara kerja lembaga tersebut (Hanifa, 2019).

Dalam penelitian yang saya laukan ini, saya mengumpulkan beberapa laporan pertanggungjawaban organisasi yang ada di Universitas Sarjanawiyata Tamansiswa. Dari 4 organisasi yang ada di Fakultas Ekonomi UST antara lain MMFE (Majelis Mahasiswa Fakultas EKonomi), IMPSM (Ikatan Mahasiswa Progam Studi Manajemen), IMPSA (Ikatan Mahasiswa Progam Studi Akuntansi), UKM (Unit Kegiatan Mahasiswa) Futsal FE UST hanya 2 organisasi yang mencantumkan laporan keuangan ke dalam laporan pertanggungjawabannya yaitu organisasi MMFE (Majelis Mahasiswa Fakultas Ekonomi) 2020 yang memiliki pemasukan sebesar Rp.14.000. 000, pengeluaran Rp.13.858.000 dan kas Rp.142.000, organisasi IMPSM (Ikatan Mahasiswa Progam Studi Manajemen) 2020 yang memiliki pemasukan sebesar Rp. Rp.8.521.000, pengeluaran Rp. Rp.8.395.550 dan kas Rp. Rp. 250.450

Akuntabilitas dapat diartikan sebagai bentuk pertanggungjawaban yang ditujukan kepada siapa dan untuk apa suatu organisasi (pekerja individu) bertanggung jawab (Mahsun, 2006). Dalam arti luas akuntabilitas sebagai suatu kewajiban pengelola keuangan untuk mempertanggungjawakan, menyajikan, melaporkan dan mengungkapkan aktivitas-aktivitas atau kegiatan kepada pihak yang memiliki hak dan wewenangan dalam meminta pertanggung jawaban tersebut. Keberhasilan suatu program kerja organisasi yang ada di UST menunjukkan tingkat akuntabilitas anggota maupun pemimpin organisasi yang ada di UST dan keberhasilan program kerja akan meningkatkan kualitas laporan pertanggungjawaban program kerja. Dalam menjalankan kegiatannya, sebuah organisasi tidak terlepas dari sebuah anggaran keuangan, karena dalam merealisasikan program kerjanya organisasi mahasiswa dituntut untuk menyajikan laporan penggunaan anggaran berupa laporan pertanggungjawaban sebagai bukti bahwa anggaran yang dipercayakan telah dikelola dan digunakan sebagaimana mestinya.

\section{Kualitas Laporan Pertanggungjawaban Program Kerja}

Laporan pertanggungjawaban program kerja adalah catatan mengenai informasi keuangan dalam suatu perusahaan pada suatu periode akuntansi tertentu yang dapat mengambarkan kinerja organisasi tersebut (Rosidiani, 2011). Kualitas laporan keuangan memiliki kaitan yang erat dengan kinerja perusahaan yang diwujudkan dalam laba perusaaan yang diperoleh pada tahun berjalan. Kulitas laporan pertanggungjawaban keuangan dapat meningkatkan kualitas informasi yang disajikan dalam laporan keuangan dan informasi dalam laporan pertanggungjawaban dapat bermanfaat bagi sejumlah besar pengguna apabila informasi yang disajikan dalam laporan keuangan tersebut relevan, dapat dipahami, andal dan dapat dibandingkan (Setiawati dan Lim, 2015).

\section{Akuntabilitas dalam Pengelolaan Keuangan}

Akuntabilitas merupakan salah satu kewajiban seseorang pemimpin organisasi dalam memberikan pertanggung jawaban dan menerangkan kinerja suatu organisasi kepada pihak yang memiliki wewenangan atau hak untuk meminta pertanggungjawaban meliputi keberhasilan maupun kegagalan (Siahan, 2012 dalam Hanifa, 2019). Adapun menurut Hanifa (2019) mengartikan akuntabilitas sebagai suatu pertanggungjawaban kepada publik atas setiap aktivitas yang dilakukan 


\section{Goal Setting Theory (GST)}

Goal setting theory (GST) merupakan salah satu bagian dari teori motivasi. Teori ini menjelaskan hubungan antara tujuan yang ditetapkan dengan kinerja. Konsep dasar teori ini merupakan seseorang yang memahami tujuan dapat memengaruhi perilaku kerjanya. Penekanan yang disampaikan dalam teori ini adalah perilaku seseorang diukur oleh ide (pemikiran) dan niat seseorarang dalam mencapai tujuannya. Sasaran dapat dilihat sebagai tujuan dari kinerja yang ingin dicapai oleh organisasi. Sebuah organisasi memiliki komitmen dalam mencapai tujuannya, maka hal ini dapat mempengaruhi konsekuensi kinerjanya. Teori ini juga dijelaskan bahwa dalam penetapan tujuan yang menantang serta dapat diukur hasilnya dapat meningkatkan kinerja, yang didasari dengan memiliki kemampuan dan keterampilan kerja (Intan, 2020). Organisasi memberikan kesempatan kepada pegawainya untuk ikut berpartisipasi serta mengambil tanggungjawab dan mengedepankan transpasransi dalam menetapkan tujuan dan mengelola keuangan cenderung kinerjanya lebih tinggi dibandingkan dengan tujuan dan pengelolaan keuangan yang hanya ditetapkan oleh atasan organisasi tersebut (Melia dan Sari, 2019).

\section{Good Corporate Governance (GCG)}

Good Corporate Governance (GCG) merupakan salah satu sistem yang mengatur serta dapat mengendalikan suatu organisasi untuk menciptakan nilai tambah bagi semua stakeholder dalam menekankan bahwa pentingnya hak pemegang saham dalam memperoleh informasi yang akurat, benar dan tepat waktu dan organisasi memiliki kewajiban untuk mengungkapkan (disclosure) secara tepat waktu, akurat, dan transparansi mengenai semua informasi kinerja organisasi, kepemilikan, dan stakeholder. Penerapan prinsip Good Corporate Governance dalam transparansi, partisipasi, dan akuntabilitas yang konsisten dapat meningkatkan kualitas laporan pertanggungjawaban dan juga dapat menghambat aktivitas rekayasa dalam pengelolaan keuangan (Setiawati dan Lim, 2015).

\section{Pengembangan Hipotesis}

\section{Pengaruh Akuntabilitas Dalam Pengelolaan Keuangan Terhadap Kualitas Laporan Pertanggungjawaban Program Kerja}

Akuntabilitas adalah suatu dorongan psikologis yang membuat seseorang mencoba untuk menyelesaikan kewajiban mereka dan mempertanggungjawabkan semua tindakan dan keputusan yang diambil untuk lingkungan hidup (Marina et al., 2018). Dengan demikian semakin meningkatnya rasa akuntabilitas dalam diri anggota organisasi kelembagaan yang ada di UST dalam pengelolaan keuangan atau keinginan untuk mempertanggungjawab kan kinerjanya maka akan meningkatkan kualitas lapoan pertanggungjawaban keuangan juga. Menurut Marina et al., (2018) individu dengan akuntabilitas tinggi mencurahkan usaha yang lebih besar daripada individu dengan akuntabilitas rendah saat menyelesaikan pekerjaan. Sejalan dengan penelitian yang dilakukan oleh Sugista (2017) mengungkapkkan semakin tinggi akuntabilitas dalam pengelolaan keuangan desa maka akan meningkatkan pembangunan desa. Hal ini membuktikan bahwa laporan keuangan desa dapat dipertanggungjawabkan dengan baik. Berdasarkan penjelasan diatas maka hipotesis penelitian adalah:

H1: Akuntabilitas dalam pengelolaan keuangan berpengaruh positif terhadap kualitas laporan pertanggungjawaban program kerja.

\section{METODE}

Penelitian ini menggunakan data kuantitatif dengan menggunakan data dan informasi dari kuesioner yang dibagikan kepada responden. Populasi yang digunakan pada penelitian ini merupakan mahasiswa yang ada di Fakultas Ekonomi Universitas Sarjanawiyata Tamansiswa Yogyakarta yang mengikuti kepengurusan organisasi kelembagaan dan UKM. Teknik dalam pengambilan sampel dilakukan dengan menggunakan metode convenience sampling. Jumlah sampel yang digunakan 
sebanyak 100 responden yang merupakan mahasiswa Universitas Sarjanawiyata Tamansiswa Yogyakarta.

HASIL DAN PEMBAHASAN

Hasil Penelitian

Uji Validitas

Tabel 1. Hasil Uji Validitas Konvergen

\begin{tabular}{|c|c|c|c|c|c|}
\hline & $\mathrm{X} 1$ & $\mathrm{X} 2$ & $\mathrm{X} 3$ & $\mathrm{Y}$ & KETERANGAN \\
\hline $\mathrm{X} 1.1$ & 0,684 & & & & Valid \\
\hline $\mathrm{X} 1.2$ & 0,765 & & & & Valid \\
\hline $\mathrm{X} 1.3$ & 0,801 & & & & Valid \\
\hline $\mathrm{X} 1.4$ & 0,634 & & & & Valid \\
\hline $\mathrm{X} 1.5$ & 0,857 & & & & Valid \\
\hline X1.6 & 0,745 & & & & Valid \\
\hline $\mathrm{X} 1.7$ & 0,775 & & & & Valid \\
\hline $\mathrm{X} 1.8$ & 0,751 & & & & Valid \\
\hline $\mathrm{X} 1.9$ & 0,662 & & & & Valid \\
\hline $\mathrm{X} 2.1$ & & 0,772 & & & Valid \\
\hline $\mathrm{X} 2.2$ & & 0,814 & & & Valid \\
\hline $\mathrm{X} 2.3$ & & 0,637 & & & Valid \\
\hline $\mathrm{X} 2.4$ & & 0,845 & & & Valid \\
\hline $\mathrm{X} 2.5$ & & 0,642 & & & Valid \\
\hline $\mathrm{X} 2.6$ & & 0,872 & & & Valid \\
\hline $\mathrm{X} 2.7$ & & 0,829 & & & Valid \\
\hline $\mathrm{X} 2.8$ & & 0,706 & & & Valid \\
\hline $\mathrm{X} 2.9$ & & 0,682 & & & Valid \\
\hline $\mathrm{X} 2.10$ & & 0,862 & & & Valid \\
\hline $\mathrm{X} 2.11$ & & 0,875 & & & Valid \\
\hline $\mathrm{X} 2.12$ & & 0,698 & & & Valid \\
\hline $\mathrm{X} 3.1$ & & & 0,833 & & Valid \\
\hline $\mathrm{X} 3.2$ & & & 0,628 & & Valid \\
\hline X3.3 & & & 0,830 & & Valid \\
\hline X3.4 & & & 0,755 & & Valid \\
\hline X3.6 & & & 0,831 & & Valid \\
\hline $\mathrm{X} 3.7$ & & & 0,889 & & Valid \\
\hline $\mathrm{X} 3.8$ & & & 0,657 & & Valid \\
\hline X3.9 & & & 0,884 & & Valid \\
\hline $\mathrm{X} 3.10$ & & & 0,923 & & Valid \\
\hline $\mathrm{X} 3.11$ & & & 0,662 & & Valid \\
\hline Y1 & & & & 0,888 & Valid \\
\hline $\mathrm{Y} 2$ & & & & 0,848 & Valid \\
\hline $\mathrm{Y} 3$ & & & & 0,601 & Valid \\
\hline Y4 & & & & 0,897 & Valid \\
\hline Y6 & & & & 0,882 & Valid \\
\hline Y8 & & & & 0,772 & Valid \\
\hline Y9 & & & & 0,917 & Valid \\
\hline
\end{tabular}




\begin{tabular}{|c|c|c|c|c|c|}
\hline & $\mathrm{X} 1$ & $\mathrm{X} 2$ & $\mathrm{X} 3$ & $\mathrm{Y}$ & KETERANGAN \\
\hline Y10 & & & & 0,911 & Valid \\
\hline $\mathrm{Y} 12$ & & & & 0,864 & Valid \\
\hline
\end{tabular}

Sumber: Data Primer, 2021, diolah

Hasil uji validitas pada penelitian ini terungkap bahwa semua butir pernyataan dinyataan valid. Hal ini ditunjukan dengan nilai loading factor di atas 0,50.

\section{Uji Reliabilitas}

Tabel 2. Hasil Uji Reliabilitas

\begin{tabular}{cccc} 
& Reliability Composite & Cronbanch's Alpha & Keterangan \\
\hline $\mathrm{X}$ & 0,944 & 0,934 & Reliabel \\
$\mathrm{Y}$ & 0,958 & 0,949 & Reliabel \\
\hline
\end{tabular}

Sumber: Data Primer, 2021, diolah

Berdasarkan tabel 2 diatas menandakan bahwa semua variabel dinyatakan reliabel dengan nilai composite reliability di atas 0,70, sedangkan nilai cronbanch's Alpha diatas 0,60

Tabel 3. Nilai R-Square

\begin{tabular}{cc}
\hline Variabel & R-Square \\
\hline Y & 0,852 \\
\hline Sumber: Data Primer, 2021, diolah
\end{tabular}

Berdasarkan tabel 3 diatas, dapat diketahui bahwa nilai $R$-square pada variabel Y memiliki nilai sebesar 0,852 yang termasuk dalam kategori kuat

Tabel 4. Nilai Path Coefficient

\begin{tabular}{cccccc}
\hline & $\begin{array}{c}\text { Original } \\
\text { Sampel }(O)\end{array}$ & $\begin{array}{c}\text { Sampel } \\
\text { Mean }(M)\end{array}$ & $\begin{array}{c}\text { Standart } \\
\text { Deviasi }\end{array}$ & $\begin{array}{c}\text { T Statistic } \\
(\text { O/STERR })\end{array}$ & P-Values \\
\hline $\mathrm{X}=>\mathrm{Y}$ & 0,976 & 0,948 & 0,147 & 6,640 & 0,000 \\
\hline
\end{tabular}

Sumber: Data Primer, 2021, diolah

Hubungan antara Hubungan antara X3 dan Y yaitu signifikan dengan nilai T-statistik 6,640 $(>1,96)$. Nilai original sampel estimate positif 0,976 . H1 yang menyatakan akuntabilitas dalam pengelolaan keuangan berpengaruh positif terhadap kualitas laporan pertanggungjawaban program kerja diterima.

\section{Pembahasan}

Hasil pengujian hipotesis menunjukan bahwa nilai T-statistik sebesar 6,640 $(>1,96)$ dan nilai original sampel estimate 0,976 . Artinya akuntabilitas dalam pengelolaan keuangan organisasi yang ada di UST berpengaruh positif terhadap kualitas laporan pertanggungjawaban program kerja, sehingga H1 yang menyatakan akuntabilitas dalam pengelolaan keuangan memiliki pengaruh positif terhadap kualitas laporan pertanggungjawaban program kerja diterima,

Hasil pengujian ini jika dikaitkan dengan Goal Setting Theory (GST), dimana menjelaskan bahwa individu yang memahami tujuan (sasaran) anggaran yang jelas dengan adanya tanggungjawab (akuntabilitas) dalam pengelolaan keuangan akan memiliki prestasi kerja (kinerja) lebih baik dalam menyajikan laporan pertanggungjawaban yang berkualitas, dibandingkan dengan individu yang tidak mengetahui tujuan (sasaran) anggaran secara jelas serta tidak berpartisipasi dan bertanggungjawab 
dalam pengelolaan keuangan. Didukung oleh prinsip Good Corporate Governance yang menyatakan bahwa transparansi, partisipasi, dan akuntabilitas yang secara konsisten dalam mengelola keuangan terbukti dapat meningkatkan kualitas laporan pertanggungjawaban dan juga dapat menghambat aktivitas rekayasa dalam pengelolaan keuangan, maka dengan adanya akuntabilitas dalam pengelolaan keuangan dapat meningkatkan kualitas laporan pertanggungjawaban prrogram kerja kelembagaan dan UKM yang ada di UST. Penelitian ini sejalan dengan penelitian yang dilakukan oleh Sugista (2017) yang mengemukakan semakin tinggi akuntabilitas pengelolaan keuangan desa maka akan meningkatkan pembangunan desa. Hal ini menunjukkan bahwa laporan pertanggungjawaban keuangan desa dapat dipertanggungjawabkan dengan baik.

\section{SIMPULAN}

Berdasarkan hasil penelitian ini dapat disimpulkan bahwa akuntabilitas dalam pengelolaan keuangan berpengaruh positif terhadap kualitas laporan pertanggungjawaban program kerja.

\section{Keterbatasan Penelitian}

Penelitian ini hanya mencakup 1 variabel independen yaitu akuntabilitas dan satu variabel dependen yaitu kualitas laporan pertanggungjawaban (LPJ) program kerja. Penelitian ini hanya menggunakan 1 sumber penelitian yaitu menggunakan kuesioner. Hal ini menunjukkan bahwa kesimpulan yang diambil hanya berdasarkan pada data yang terkumpul melalui kuesioner tersebut.

\section{Saran}

Penelitian selanjutnya diharapkan dapat menambah variabel baru atau berbeda selain veriabel akuntabilitas dan kualitas laporan pertanggungjawaban yang dipakai dalam penelitian ini, contohnya seperti pengaruh pengelolaan anggaran terhadap kualitas laporan pertanggungjawaban dengan motivasi sebagai variabel moderasi. Penelitian selanjutnya diharapkan untuk menggunakan metode wawancara serta angket terbuka dalam penelitian, agar data yang diperoleh sesuai dengan keadaan yang sebenarnya.

\section{DAFTAR PUSTAKA}

Hanifa, A. (2019). Transparansi Dan Akuntabilitas Pengelolaan Keuangan Organisasi Mahasiswa Iain Surakarta. 101.

Intan Rohmah Saputri. (2020). Pengaruh Kejelasan Sasaran Anggaran Dan Partisipasi Anggaran Tehadap Kinerja Organisasi Dengan Gaya Kepemimpinan Sebagai Variabel Pemoderasi (Studi Pada Kelembagaan Dan Ukm Di Universitas Sarjanawiyata Tamansiswa) (Pp. 1-99).

Mahsun. (2006). Pengukuran Kinerja Sektor Publik. Akuntansi Sektor Publik, Ed.I(Yogyakarta).

Marina, S., Rura, Y., \& A, T. (2018). The Effect Of Competence Of Human Resources And The Use Of Information Technology On The Quality Of Financial Report With Internal Control System And Organizational Commitment As Moderation Variable. International Journal Of Advanced Research, 6(12), 517-525.

Melia, P., \& Sari, V. F. (2019). Pengaruh Akuntabilitas Publik, Kejelasan Sasaran Anggaran Dan Partisipasi Anggaran Terhadap Kinerja Manajerial (Studi Empiris Pada Satuan Kerja Perangkat Daerah Kabupaten Solok Selatan). Jurnal Eksplorasi Akuntansi, 1(3), 1068-1079.

Rosidiani, H. T. (2011). Pengaruh Sistem Pengendalian Internal, Audit Laporan Keuangan, Dan Penerapan Good Corporate Governance Terhadap Kualitas Laporan Keuangan. Skripsi Universitas Islam Negeri Syarif Hidayatullah Jakarta.

Setiawati, L. W., \& Lim, M. (2015). Jurnal Akuntansi Jurnal Akuntansi. Badruzaman Jajang, 12(1), $29-57$.

Sugista, R. A. (2017). Pengaruh Transpansi, Akuntabilitas, Dan Partisipasi Masyarakat Dalam Pengelolaan Keuangan Desa Terhadap Pembangunan Desa. Jurnal Sosiologi, 01, 18. 